\title{
Which Pulmonary Function Tests Best Differentiate Between COPD Phenotypes?
}

\author{
Steve H Salzman MD
}

\author{
Introduction \\ Do PFT Features Distinguish Asthma From COPD? \\ Do We Need New Diagnostic Categories? \\ Should the Diagnosis of COPD Be Based on Pre- or Post-Bronchodilator \\ Results? \\ Do All Patients With Post-Bronchodilator Air Flow Limitation Have \\ COPD? \\ Does a Normal $D_{\text {LCO }}$ Rule Out Emphysema? \\ Is $\mathrm{D}_{\mathrm{LCO}}$ Helpful in Predicting Exercise Oxygen Desaturation? \\ Are Measurements of Hyperinflation Helpful? \\ Is Air Flow Obstruction a Risk Factor for Lung Cancer? \\ Are Genetic Studies Helpful in COPD Phenotype Definitions? \\ Summary
}

We are still at the early phase of finding useful phenotypes in COPD that can guide therapy. However, in a simple sense, "sick patients die." Many phenotypic measurements of severity correlate with mortality in COPD: $\mathrm{FEV}_{1}$, the ratio of inspiratory capacity to total lung capacity (IC/TLC), diffusing capacity of the lung for carbon monoxide $\left(\mathrm{D}_{\mathrm{LCO}}\right), 6$-min walk distance, and maximum oxygen $\left(\mathrm{O}_{2}\right)$ consumption or maximum watts on exercise testing. However, composite parameters, such as the BODE index (body mass index, air flow obstruction, dyspnea, exercise capacity), perform better, likely because they capture different aspects of severity that affect functional impairment and risk of death. Bronchodilator responsiveness is just a relative feature that aids in distinction of asthma and COPD but is not diagnostic in this use. A normal $\mathrm{D}_{\mathrm{LCO}}$ helps to rule out exercise-induced $\mathrm{O}_{2}$ desaturation, but those with a low $\mathrm{D}_{\mathrm{LCO}}$ and COPD need exercise measurements to confirm desaturation. Currently, pulmonary function tests (PFTs) alone do not define subsets who respond to particular therapies. The presence of air flow obstruction and its severity increase the risk of lung cancer in COPD patients. Inflammatory biomarkers (exhaled nitric oxide and eosinophilia in sputum or bronchoalveolar lavage fluid) help distinguish asthma from COPD. Genetics is a promising area to elucidate pathophysiology and treatment for asthma and COPD, but currently alpha-1 antitrypsin deficiency is the only genetically-determined phenotype that has relevance for COPD management. The best promise for the future seems to be in composite phenotypes or scores, both for distinguishing asthma from COPD, and for guiding therapeutic options. It may be better to throw out the old, limiting diagnostic concepts. If, instead, we start from outcomes of interest, perhaps we can work back to predictors of these outcomes, and organize new diagnostic entities that have predictive relevance for treatment choices, functional outcomes, and mortality. Key words: pulmonary function tests; COPD; phenotypes; mortality; outcomes; prognosis. [Respir Care 2012;57(1):50-57. () 2012 Daedalus Enterprises] 


\section{Which Pulmonary Function Tests Best Differentiate Between COPD Phenotypes?}

\section{Introduction}

Chronic obstructive pulmonary disease (COPD) has traditionally been viewed as a clinical syndrome made up of patient subtypes, mostly chronic bronchitis and emphysema, with the concept that many patients expressed mixed characteristics. ${ }^{1}$ Another characterization has been Type A (Pink Puffer) and Type B (Blue Bloater) COPD, clinicalpathophysiologic syndromes that clustered together and were thought to represent points on a continuum representing different pathophysiology. ${ }^{1}$ For a long time there has been interest in clinical features that correlate with natural history, death, and other important outcomes. More recently, under the rubric of the term "phenotypes," this approach has been formalized into the idea of "a single or combination of disease attributes that describe differences between individuals with COPD as they relate to clinically meaningful outcomes (symptoms, exacerbations, response to therapy, rate of disease progression, or death)."2 This current definition of phenotype makes the subtle but important practical distinction that a phenotype is meant to correlate with clinically meaningful outcomes, not pathophysiologic mechanisms. In that sense a phenotype, which may be a single clinically observable aspect or a collection of such measures, is useful to the extent that it predicts some outcome of importance. Although it is presumed that these would also relate to pathophysiological mechanisms, the emphasis is on predicting outcomes. The importance of a phenotype is in its ability to guide therapeutic choices or express risk for a variety of outcomes (particularly rapid disease progression, exacerbations, or death).

A well established example of this is the COPD phenotype that predicts increased survival after lung-volumereduction surgery (LVRS). ${ }^{3}$ Among patients with severe emphysema, the sub-group phenotype of upper lobe predominant emphysema on chest computed tomography (CT) imaging and low maximum exercise tolerance had improved survival with LVRS, compared to usual medical management. ${ }^{3}$ However, the sub-phenotype defined by

Dr Salzman is affiliated with the Division of Pulmonary and Critical Care Medicine, Department of Medicine, Winthrop-University Hospital, Mineola, New York, and with the School of Medicine, State University of New York at Stony Brook, Stony Brook, New York.

Dr Salzman presented a version of this paper at the 48th RESPIRATORY CARE Journal Conference, "Pulmonary Function Testing," held March 2527, 2011, in Tampa, Florida.

The author has disclosed no conflicts of interest.

Correspondence: Steve H Salzman MD, Division of Pulmonary and Critical Care Medicine, Winthrop-University Hospital, Mineola NY 11501. E-mail: ssalzman@winthrop.org.

DOI: $10.4187 /$ respcare.01585
Table 1. Candidate COPD Phenotypes*

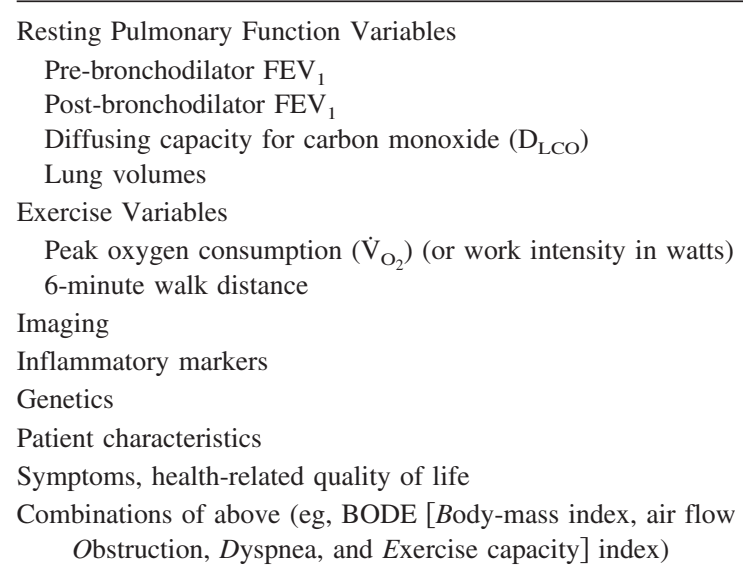

* Note: an outcome can also be a phenotype.

(1) an $\mathrm{FEV}_{1} \leq 20 \%$ of predicted values, and (2) diffusing capacity for carbon monoxide $\left(\mathrm{D}_{\mathrm{LCO}}\right) \leq 20 \%$ of predicted values or homogenous emphysema on $\mathrm{CT}$, were shown to have lower survival with LVRS. These COPD phenotypes defined by combined physiologic-imaging features identify groups that should be treated differently based on outcome data. Candidate phenotypes other than pulmonary function test (PFT) parameters are listed in Table 1. Note that some clinical features can be both a phenotype and an outcome, and that some phenotypes are composites of clinically measureable features.

In clinical practice and guidelines, spirometry has a core role in assessing patients with COPD. The parameters, $\mathrm{FEV}_{1}, \mathrm{FVC}$, and $\mathrm{FEV}_{1} / \mathrm{FVC}$ are still the main measurements used. $\mathrm{FEV}_{1} / \mathrm{FVC}$ is used to define obstructive disease, ${ }^{4,5}$ and $\mathrm{FEV}_{1}$ is used to define severity. ${ }^{4}$ However, these "big three" parameters explain only $10-25 \%$ of symptoms, disease-related quality of life, and exercise performance. ${ }^{2}$ Phenotypes defined by clusters of parameters, for example the BODE index (Body-mass index, air flow Obstruction, Dyspnea, and Exercise capacity index) may perform better. ${ }^{6}$

\section{Do PFT Features Distinguish Asthma From COPD?}

In general, most clinicians have no difficulty distinguishing asthma from COPD. Most asthmatics are nonsmokers, but the vast majority of COPD is caused by tobacco use. Atopy is very frequent in asthma, but less common in COPD. The main PFT phenotypic factors distinguishing the 2 are listed in Table 2. However a substantial group of patients have overlapping features. How well do PFT parameters distinguish these 2 conditions? Specifically, does lack of bronchodilator response rule out asthma in a smoking adult? 


\section{Which Pulmonary Function Tests Best Differentiate Between COPD Phenotypes?}

Table 2. Typical Contrasting Pulmonary Function Testing Features of Asthma and COPD Phenotype

\begin{tabular}{|c|c|c|}
\hline Clinical Feature & Asthma & COPD \\
\hline Bronchodilator response & Mostly yes & Mostly no \\
\hline $\begin{array}{l}\text { Size of bronchodilator } \\
\text { response }\end{array}$ & Larger & Smaller \\
\hline Hyperinflation & $\begin{array}{l}\text { Only with } \\
\text { exacerbation }\end{array}$ & $\begin{array}{l}\text { At rest, except in mild } \\
\text { COPD }\end{array}$ \\
\hline $\begin{array}{l}\text { Diffusing capacity for } \\
\text { carbon monoxide }\end{array}$ & Normal & $\begin{array}{l}\text { Low unless pure chronic } \\
\text { bronchitis }\end{array}$ \\
\hline Lung elastic recoil & Normal & Low \\
\hline
\end{tabular}

Kesten and Rebuck evaluated whether the short-term response to inhaled $\beta$ agonist distinguished asthma and COPD. ${ }^{7}$ They evaluated 287 patients with asthma and 108 patients with COPD. Patients with asthma, compared to COPD, were younger ( $49 \mathrm{y}$ vs $66 \mathrm{y}, P<.01$ ), had larger increase in $\mathrm{FEV}_{1}$ after inhaled bronchodilator $(330 \mathrm{~mL}$ vs $130 \mathrm{~mL}, 16 \%$ vs $11 \%$, both $P<.01)$, but similar FVC responses $(290 \mathrm{~mL}$ vs $250 \mathrm{~mL}$, NS), and lesser degrees of hyperinflation (residual volume [RV] $2.59 \mathrm{~L}$ [146\%] vs $3.54 \mathrm{~L}$ [169\%]), RV/total lung capacity (TLC) $42 \%$ vs $55 \%$, all $P<.01$ ) except for similar TLC measurements (6.27 L [112\%] vs 6.49 L [114\%], NS). However, when focusing on the sensitivity and specificity of various cutpoints for defining short-term bronchodilator responses, neither $\mathrm{FEV}_{1}$ nor FVC performed very well at distinguishing asthma from COPD. For example, using the cut points closest to those currently recommended in the 2005 American Thoracic Society (ATS)/European Respiratory Society (ERS) guidelines for interpretation of PFTs, ${ }^{4}$ a change of at least $200 \mathrm{~mL}$ in $\mathrm{FEV}_{1}$ and a $10 \%$ change had a sensitivity of 58\% and specificity of $77 \%$ for the diagnosis of asthma. If the more stringent cut point of requiring a $15 \%$ increase was used (as is often required in research studies), it only increased the specificity to $81 \%$, at the cost of a lower sensitivity of $43 \%$. They concluded that acute responses in $\mathrm{FEV}_{1}$ or FVC could not be used to distinguish COPD from asthma.

Tashkin and colleagues reported on the surprisingly large percent of COPD patients with substantial bronchodilator responses in the UPLIFT (Understanding Potential Long-term Impacts on Function with Tiotropium) trial. ${ }^{8}$ It should be noted that the protocol used in the 5,756 COPD patients involved 3 features that likely differ from the usual clinical PFT laboratory and would emphasize bronchodilator responsiveness: relatively large doses of both an anticholinergic and $\beta$-agonist inhaler $(80 \mu \mathrm{g}$ of ipratropium and $440 \mu \mathrm{g}$ of albuterol), waiting a full $90 \mathrm{~min}$ for the post-bronchodilator spirometry. Of the study patients, $53.9 \%$ had $\geq 12 \%$ and $>200 \mathrm{~mL}$ improvement in $\mathrm{FEV}_{1}$, and $65.5 \%$ had $\geq 15 \%$ improvement in $\mathrm{FEV}_{1}$. The former is the current recommended ATS/ERS guideline
Table 3. Pulmonary Function Test Parameters and Inflammatory Measures to Distinguish Asthma from COPD*

\begin{tabular}{lc}
\hline \hline & $\begin{array}{c}\text { Area Under the } \\
\text { ROC Curve }\end{array}$ \\
\hline Reversibility to bronchodilator & 0.71 \\
Reversibility to inhaled corticosteroid & 0.73 \\
Diffusing capacity/alveolar volume & 0.66 \\
Residual volume & 0.63 \\
Bronchoalveolar lavage, \% eosinophils & 0.95 \\
Sputum, \% eosinophils & 0.88 \\
Exhaled nitric oxide & 0.86 \\
* See Reference 9. & \\
ROC $=$ receiver operating characteristic & \\
\hline
\end{tabular}

criteria defining positive or significant acute bronchodilator response (for $\mathrm{FEV}_{1}$ or FVC), while the latter may be a more appropriate criterion for severe COPD patients, who are unable to meet the criterion for an absolute change of $200 \mathrm{~mL}$, due to small absolute value of their baseline $\mathrm{FEV}_{1}$ in $\mathrm{mL}$. As the Global Initiative for Chronic Obstructive Lung Disease (GOLD) stage increased from II to IV (increased severity) increasing percentages of COPD patients had acute bronchodilator responsiveness by FVC alone (not $\mathrm{FEV}_{1}$ ). This varied from about $7 \%$ in Stage II, $25 \%$ in Stage III, to $49 \%$ in Stage IV. Using the ATS criteria for bronchodilator response (either $\mathrm{FEV}_{1}$ or FVC), over $60 \%$ of all COPD patients in Stage II through IV had an acute bronchodilator response.

Fabbri and co-workers looked at a group of patients with fixed air flow obstruction, which they defined as post-bronchodilator $\mathrm{FEV}_{1}<0.70 .{ }^{9}$ Using a composite clinical picture to assign 19 as asthma and 27 as COPD, they sought to identify which clinical features, including PFTs, were best at distinguishing the 2 conditions. COPD patients were more likely than asthma patients to have smoked tobacco (24 former, 4 current vs 14 never, 5 former, $P<.001$ ), to have higher RV percentage predicted $(131.8 \%$ vs $106.6 \%, P<.01)$, to have lower $\mathrm{D}_{\mathrm{LCO}}$ percentage predicted $(65.4 \%$ vs $85.0 \%, P<.001)$, to have lower $\mathrm{P}_{\mathrm{aO}_{2}}(72.1 \mathrm{~mm} \mathrm{Hg}$ vs $78.5 \mathrm{~mm} \mathrm{Hg}, P<.05)$, to have smaller acute response of $\mathrm{FEV}_{1}$ to inhaled bronchodilator $(122.7 \mathrm{~mL}$ vs $251.7 \mathrm{~mL}[P<.05]$ and $4.5 \%$ predicted vs $8.7 \%$ predicted $[P<.01])$, smaller change in $\mathrm{FEV}_{1}$ after inhaled corticosteroid (3.6\% predicted vs $12.1 \%$ predicted, $P<.01$ ), and higher CT emphysema score (3.6 vs 0.6 , $P<.05)$.

They sought to identify which features best distinguished COPD from asthma by calculating the area under the receiver operating characteristic (ROC) curve, with higher values identifying phenotype features with the best combination of sensitivity and specificity. ${ }^{9}$ Table 3 identifies that inflammatory markers, such as eosinophilia in sputum 


\section{Which Pulmonary Function Tests Best Differentiate Between COPD Phenotypes?}

and bronchoalveolar lavage fluid, and exhaled nitric oxide, were better than PFT-based tests at distinguishing COPD from asthma.

These data, taken together, suggest that PFT phenotypes alone do not adequately distinguish COPD from asthma, and composite clinical phenotypes perform better. Lack of a bronchodilator response alone should not rule out asthma in a smoking adult. Conversely, the presence of a bronchodilator response cannot rule out COPD.

\section{Do We Need New Diagnostic Categories?}

The suboptimal performance of individual phenotypic features in distinguishing types of obstructive lung disease may reflect a problem with our names and categories for the diseases rather than inadequacies of the tests used. Weatherall et al defined distinct obstructive lung disease phenotypes in the spectrum of COPD and asthma using cluster analysis, a data analysis approach that attempts to define clinical subtypes by the natural way that clinical phenotypic features self-associate in actual individual subjects, rather than in preexisting diagnostic categories. ${ }^{10}$ This study used a random population sample to identify "clusters" by identifying subjects more similar to each other than those in other groups. In this manner they identified 5 clusters of unequal size: (1) severe and markedly variable air flow obstruction with features of atopic asthma, chronic bronchitis, and emphysema; (2) features of emphysema alone; (3) atopic asthma with eosinophilic airways inflammations; (4) mild air flow obstruction without other dominant phenotypic features; (5) chronic bronchitis in nonsmokers. ${ }^{10}$ It is possible that these more naturally defined diagnostic categories, or perhaps diagnostic categories (phenotypes) that relate to likelihood to respond to a specific therapy will serve us better than pathophysiologically defined categories. Our scientific model of disease would lead us to expect that these approaches are convergent, but examination of the history of science suggests that models in science are conservative even when the data no longer fit the models, often leading to paradigm shifts that occur suddenly and are often opposed by a resistance to change by many investigators. ${ }^{11}$

\section{Should the Diagnosis of COPD Be Based on Pre- or Post-Bronchodilator Results?}

One of the cardinal features in distinguishing COPD from asthma is degree of reversibility. This would seem to require both pre- and post-bronchodilator testing to make the diagnosis of COPD. However, the immediate response, and response over days, weeks, or months do not always correlate, yet all characterize reversibility. Serial assessment of pre-bronchodilator spirometry over longer periods of time may be more helpful than response in a single session.
An advantage of using pre-bronchodilator testing is that reference values are established without bronchodilator. ${ }^{12}$ In that sense, a pre-bronchodilator result below the lower limit of normal is an "abnormal test result" even if the administration of bronchodilator pushes these values into the normal range. In addition, requiring post-bronchodilator testing to make a diagnosis of COPD increases the complexity of testing, as most primary care settings will likely only perform pre-bronchodilator testing on portable spirometry equipment.

The advantages of doing pre- and post-bronchodilator testing is to aid the distinction of COPD from asthma, acknowledging that is just one of many features that helps make that differential diagnosis clear. It is sometimes cited that post-bronchodilator testing has the advantage of better correlation with mortality. An analysis of this issue by Hansen et al demonstrated a more nuanced conclusion. ${ }^{13}$ Rather than reversibility of obstruction per se having prognostic value, their data suggested that the highest attainable $\mathrm{FEV}_{1}$ correlates best with mortality, whether that is before or after bronchodilator.

\section{Do All Patients With Post-Bronchodilator Air Flow Limitation Have COPD?}

This question raises several issues. First, some patients with an $\mathrm{FEV}_{1} / \mathrm{FVC}$ below the lower limit of normal (the defining characteristic of obstructive lung disease ${ }^{4}$ ) have asthma rather than COPD, as shown in the Fabbri et al study discussed earlier. ${ }^{9}$ Another implication of this question is what is the importance of Stage I COPD? According to the GOLD guidelines, Stage I COPD (mild COPD) is defined by mild air flow obstruction $\left(\mathrm{FEV}_{1} / \mathrm{FVC}<0.70\right.$ with $\mathrm{FEV}_{1}>80 \%$ predicted) and sometimes, but not always, chronic cough and sputum production. ${ }^{5}$ Do patients with asymptomatic spirometric abnormality consistent with Stage I COPD really have the disease COPD, or are they just normal variants below the 5th percentile? Hoogendoorn and co-workers did a systematic literature review to address this and other issues. ${ }^{14}$ They identified 37 randomized controlled trials and cohort studies that would allow them to identify the association between lung function and exacerbation frequency in COPD. They analyzed the exacerbation frequency as a function of the mean $\mathrm{FEV}_{1} \%$ predicted in each study, and translated this into GOLD stages, defining mild as $90 \%$ predicted, moderate as $65 \%$ predicted, severe as $42 \%$ predicted, very severe as $42 \%$ predicted, and very, very severe as $23 \%$ predicted. Exacerbations are an important outcome in COPD because they are associated with mortality, health-related quality of life, and healthcare utilization and cost. However studies use varying definitions and methods to identify exacerbations. In this systematic review they separated studies into those that use symptom-based definitions of exacerbation (self- 


\section{Which Pulmonary Function Tests Best Differentiate Between COPD Phenotypes?}

reported exacerbation), which generally results in higher estimates because it includes exacerbations in which the patient does not present to a physician, and event-based definitions of exacerbations (such as doctor's visit, use of antibiotics or systemic steroids, or both, or hospitalization), which are more objective, but can vary by treatment setting, due to different practice patterns. Severe exacerbation was defined as one leading to hospitalization. In their analysis for mild COPD patients, event-based exacerbations were $0.82(0.46-1.49)$ annually, symptom-based exacerbation were 1.15 (0.67-2.07) annually, and severe exacerbations were $0.11(0.02-0.56)$ annually. Annual exacerbation frequency increased in all categories of exacerbation as severity of COPD increased. These data suggest that even Stage I COPD is associated with clinically important outcomes, which supports regarding this as an early form of COPD. However, even if this is an early form of COPD with increased morbidity, whether or not these patients benefit from routine use of inhaler medication is a separate question.

\section{Does a Normal $D_{\text {LCO }}$ Rule Out Emphysema?}

In patients with air flow obstruction, the presence of a low $\mathrm{D}_{\mathrm{LCO}}$ has been used to diagnosis emphysema, as opposed to asthma or non-emphysematous COPD. ${ }^{4} \mathrm{We}$ know that the single PFT measurement that correlates best with severity of emphysema on pathology is $\mathrm{D}_{\mathrm{LCO}} \cdot{ }^{15}$ However, the combination of $\mathrm{FEV}_{1}$, TLC and $\mathrm{D}_{\mathrm{LCO}}$ better correlates with severity of emphysema. ${ }^{15}$ As chest CT scans are increasingly used in various clinical settings, it has become clear that some patients with an imaging-based diagnosis of emphysema have reduced $\mathrm{D}_{\mathrm{LCO}}$, with normal or nearnormal lung mechanics $\left(\mathrm{FEV}_{1}, \mathrm{FVC}, \mathrm{FEV}_{1} / \mathrm{FVC}\right.$, and lung volumes). ${ }^{16}$ This might be thought of as emphysema without COPD, or even "COPD without O" (latter, personal communication, Paul L Enright, 2011).

Can we confidently state that the presence of normal $\mathrm{D}_{\mathrm{LCO}}$ on PFTs means a patient does not have emphysema? Lee and colleagues evaluated 197 COPD patients and 103 healthy adult subjects in Korea to address this issue. ${ }^{17}$ They questioned whether the lower 5 th percentile was an adequate cut-point for making this distinction. All subjects had volumetric CT scans with software-based densitometry measurement and PFTs, including spirometry and $\mathrm{D}_{\mathrm{LCO}}$. The $\mathrm{D}_{\mathrm{LCO}}$ percentage predicted correlated well with the volume fraction of the lung with a density $<950$ Hounsfield units (percent of lung with emphysema) $(\mathrm{r}=-0.632$, $P<.001$ ). The lower 5 th percentile used as the lower limit of normal for $\mathrm{D}_{\mathrm{LCO}}$ had a sensitivity of $68.3 \%$ and specificity of $98.1 \%$ for differentiating COPD patients with emphysema from healthy subjects. In this setting a low $\mathrm{D}_{\text {LCO }}$ suggests emphysema, but a normal value did not rule out emphysema. Using ROC curve analysis (area un- der the curve $[\mathrm{AUC}]=0.92$ ), the lower 9th percentile performed best, with a sensitivity of $79.4 \%$ and specificity of $94.2 \%$. However, when the comparison group was COPD patients without emphysema, $\mathrm{D}_{\mathrm{LCO}}$ discriminated less well between groups. The lower 5th percentile diagnosed emphysema among COPD patients with a sensitivity of $68.3 \%$ and a specificity of $84.5 \%$. The lower 9 th percentile worked better based on ROC analysis (AUC $=0.84$ ), with a sensitivity of $79.4 \%$ and specificity of $77.5 \%$.

These data suggest that among patients with air flow obstruction, $\mathrm{D}_{\mathrm{LCO}}$ is helpful but not definitive in either excluding or confirming a diagnosis of emphysema. When lung mechanics are normal (normal spirometry and lung volumes), "isolated" reduction in $\mathrm{D}_{\mathrm{LCO}}$ does suggest emphysema, but normal $\mathrm{D}_{\mathrm{LCO}}$ does not rule it out. As this study did not include patients with pulmonary vascular disease or mild/early interstitial lung disease, we should be cautious in concluding that the pattern of "isolated" low diffusing capacity suggests emphysema, as it is also associated with these 2 conditions. ${ }^{4}$ Note that the Lee study used a Korean reference set, so the performance of reference sets in use in North America and other regions may perform differently. ${ }^{18}$

\section{Is $\mathbf{D}_{\mathrm{LCO}}$ Helpful in Predicting Exercise Oxygen Desaturation?}

Studies from the 1980s indicated that $\mathrm{D}_{\mathrm{LCO}}$ was more useful for excluding exercise oxygen $\left(\mathrm{O}_{2}\right)$ desaturation during exercise in COPD patients than in ruling it in. ${ }^{19,20}$ Owens and colleagues found that a $\mathrm{D}_{\mathrm{LCO}}$ of $55 \%$ predicted had $82 \%$ specificity and $100 \%$ sensitivity for excluding exercise-induced $\mathrm{O}_{2}$ desaturation in COPD. ${ }^{18}$ Ries and coworkers found that an $\mathrm{FEV}_{1} / \mathrm{FVC} \geq 0.50$ and $\mathrm{D}_{\mathrm{LCO}} \geq 20 \mathrm{~mL} / \mathrm{min} / \mathrm{mm} \mathrm{Hg}$ were $100 \%$ predictive in excluding a fall in exercise $\mathrm{P}_{\mathrm{O}_{2}}$ in 40 patients with COPD. ${ }^{20}$

More recently, using a large database in patients with mixed pulmonary diseases, the ability of $\mathrm{D}_{\mathrm{LCO}}$ to predict exercise $\mathrm{O}_{2}$ desaturation $\geq 4 \%$ on a 3-min step-test was examined. ${ }^{21}$ Obstructive lung disease was present in $74 \%$ of subjects, and restrictive diseases in 5.6\% . A low $\mathrm{D}_{\mathrm{LCO}}$ was present in $56 \%$ of patients with restriction, and $33 \%$ of patients with an obstructive pattern. If $\mathrm{D}_{\mathrm{LCO}}$ was low, the odds ratio was 34 for $\mathrm{O}_{2}$ desaturation in restrictive patients and 18 in the obstructive group. Overall, for all subjects, a cut point of $62 \%$ predicted was most useful. When $\mathrm{D}_{\mathrm{LCO}}$ was $<62 \%$ predicted, using the Miller et al reference equation, ${ }^{22}$ the sensitivity and specificity for $\mathrm{O}_{2}$ desaturation were both approximately $75 \%$.

These studies suggest that a reduced $\mathrm{D}_{\mathrm{LCO}}$ is not sufficiently accurate to predict exercise $\mathrm{O}_{2}$ desaturation without directly measuring it. However, among patients with COPD, the presence of a low $\mathrm{D}_{\mathrm{LCO}}$ warrants measurement 


\section{Which Pulmonary Function Tests Best Differentiate Between COPD Phenotypes?}

Table 4. Risk of Death From Any Cause and From Respiratory Failure: Univariate Logistic Regression Analysis*

\begin{tabular}{|c|c|c|c|c|}
\hline & \multicolumn{2}{|c|}{ Any Cause } & \multicolumn{2}{|c|}{ Respiratory Failure } \\
\hline & $\begin{array}{l}\text { Relative } \\
\text { Risk }\end{array}$ & $95 \% \mathrm{CI}$ & $\begin{array}{l}\text { Relative } \\
\text { Risk }\end{array}$ & $95 \% \mathrm{CI}$ \\
\hline $\mathrm{FEV}_{1}, 10 \mathrm{~mL}$ less & 3.846 & $2.551-5.780$ & 8.621 & $4.926-14.925$ \\
\hline 6MWD, $1 \mathrm{~m}$ less & 1.010 & $1.008-1.011$ & 1.011 & $1.009-1.013$ \\
\hline $\begin{array}{l}\text { BODE index, one } \\
\text { point more }\end{array}$ & 1.644 & $1.505-1.796$ & 1.824 & $1.641-2.027$ \\
\hline IC/TLC, $1 \%$ lower & 1.112 & $1.087-1.139$ & 1.142 & $1.109-1.175$ \\
\hline \multicolumn{5}{|c|}{$\begin{array}{l}\text { * See Reference } 26 . \\
6 \mathrm{MWD}=\text { distance walked during the } 6 \text {-min walk test } \\
\text { BODE index = index combining Body-mass index, air flow Obstruction, Dyspnea, and } \\
\text { Exercise capacity } \\
\text { IC/TLC = ratio of inspiratory capacity to total lung capacity. }\end{array}$} \\
\hline
\end{tabular}

of exercise $\mathrm{O}_{2}$, often in conjunction with a 6-min walk distance test. ${ }^{23-25}$

\section{Are Measurements of Hyperinflation Helpful?}

Interpretation of the obstructive pattern on PFTs is usually based on the $\mathrm{FEV}_{1} / \mathrm{FVC}$ ratio, and severity is based on the $\mathrm{FEV}_{1}$ and $\mathrm{D}_{\mathrm{LCO}}{ }^{4}$ Lung volume, specifically TLC is used to evaluate for the presence of restriction. ${ }^{4}$ So in daily practice of PFT interpretation, lung volume measurements are not needed to establish a diagnosis of obstructive lung disease, although most include them in the "routine," "complete" study to rule out restriction, and to aid in interpretation of borderline or ambiguous cases. As we increasingly recognize that $\mathrm{FEV}_{1}$ does not fully capture patients' severity and function, ${ }^{2}$ direct and indirect measures of hyperinflation have been examined for their additional roles.

Casanova and colleagues found that in 689 COPD patients, the inspiratory capacity (IC) to TLC ratio (IC/TLC) was an independent predictor of mortality during a mean 34 months of follow-up, even when the BODE index and $\mathrm{FEV}_{1}$ were included in the analysis. ${ }^{26} \mathrm{On}$ multivariate logistic regression modeling, for every $1 \%$ decrease in IC/TLC, the relative risk of death was 1.052 (95\% CI 1.022-1.083). Using ROC curve analysis, the best cutoff value was IC/TLC $<25 \%$, with a sensitivity of $71 \%$ and specificity of $69 \%$. However, examination of their data still emphasizes the central role of $\mathrm{FEV}_{1}$, both directly and via its contribution to the BODE index (Table 4).

Martinez and co-workers, writing for the National Emphysema Treatment Trial (NETT) Research Group, reported on predictors of mortality in this randomized trial of LVRS versus medical management in COPD patients with severe emphysema. ${ }^{27}$ In multivariate analysis of these 609 patients, more severe hyperinflation measured by RV was associated with higher mortality (Table 5). In a seeming paradox, among these patients with severe emphy-
Table 5. Significant Predictors of Mortality in 609 Patients With Severe Emphysema (Using Two Multivariate Models of Mortality)*

\begin{tabular}{|c|c|c|c|c|}
\hline & \multicolumn{2}{|l|}{ Model 1} & \multicolumn{2}{|l|}{ Model 2} \\
\hline & $\begin{array}{l}\text { Hazard Ratio } \\
\quad(95 \% \mathrm{CI})\end{array}$ & $P$ & $\begin{array}{l}\text { Hazard Ratio } \\
\quad(95 \% \mathrm{CI})\end{array}$ & $P$ \\
\hline $\begin{array}{l}\text { TLC, } \% \text { predicted } \\
\quad \geq 140\end{array}$ & $0.68(0.46-1.00)$ & .05 & $0.69(0.47-1.01)$ & .06 \\
\hline $\begin{array}{l}\mathrm{RV}, \% \text { predicted } \\
\quad \geq 262\end{array}$ & $1.57(1.03-2.39)$ & .04 & $1.56(1.04-2.37)$ & .03 \\
\hline $\begin{array}{l}\mathrm{D}_{\mathrm{LCO}}, \% \text { predicted } \\
\quad \leq 21 \%\end{array}$ & $1.34(0.99-1.82)$ & .06 & $1.36(1.01-1.84)$ & .04 \\
\hline $\begin{array}{l}\text { Maximal CPET } \\
\text { workload, watts } \\
\leq 25 \text { (female) } \\
\leq 40 \text { (male) }\end{array}$ & $1.54(1.17-2.03)$ & .002 & $1.48(1.12-1.94)$ & .006 \\
\hline $\begin{array}{l}* \text { See Reference } 27 . \\
\text { TLC = total lung capacity } \\
\mathrm{RV}=\text { residual volume } \\
\mathrm{D}_{\mathrm{LCO}}=\text { diffusing capacity } \\
\mathrm{CPET}=\text { cardiopulmonary }\end{array}$ & $\begin{array}{l}\text { of the lung for carbon } 1 \\
\text { exercise testing. }\end{array}$ & noxide & ingle-breath method) & \\
\hline
\end{tabular}

sema, more severe hyperinflation measured by TLC was associated with a lower mortality (see Table 5). This may be explained by some mechanism in which inability of the chest wall to expand outward and allow a higher TLC confers a worse prognosis. This matches well with the data from Casanova et al indicating a worse prognosis with higher IC/TLC ratio. ${ }^{26}$ For a given IC, a larger TLC confers a lower IC/TLC.

However, in the NETT trial IC/TLC $<0.18$ was a significant predictor only on univariate analysis (hazard ratio $1.80,95 \%$ CI $1.39-2.34, P<.001$ ), but not on multivariate analysis. ${ }^{27}$ These seeming disparities could relate to the narrower range of COPD patients in the NETT trial (severe emphysema only). Whether hyperinflation measured relative to the reference population (\% predicted), or using internal relationships (IC/TLC, RV/TLC), is more useful in defining COPD phenotypes is not yet clear.

\section{Is Air Flow Obstruction a Risk Factor for Lung Cancer?}

Cigarette smoking is the main risk factor for lung cancer, accounting for roughly $85 \%$ of cases. Multiple studies have suggested that air flow obstruction is a risk factor for lung cancer independent of smoking, but the role of radiographic evidence for emphysema is less clear. A recent study from the Mayo Clinic enrolled 1,520 patients who were followed for 4 years for the development of lung cancer (66 cases). ${ }^{28}$ When analyzed as a continuous variable, reduced $\mathrm{FEV}_{1}$ and $\mathrm{FEV}_{1} / \mathrm{FVC}$ were associated with a subsequent diagnosis of lung cancer, with an odds ratio of $1.15(95 \% \mathrm{CI} 1.00-1.32, P=.046)$ and $1.29(95 \% \mathrm{CI}$ 


\section{Which Pulmonary Function Tests Best Differentiate Between COPD Phenotypes?}

Table 6. Presence of Air Flow Obstruction and Its Severity Predict Development of Lung Cancer Independent of Age, Smoking History, and Sex on Conditional Logistic Regression*

\begin{tabular}{lccc}
\hline \hline \multicolumn{1}{c}{ Measure } & Odds Ratio & $95 \% \mathrm{CI}$ & $P$ \\
\hline $\mathrm{FEV}_{1} \%$ predicted & & & .046 \\
$\quad 81+$ & 1.00 & $\mathrm{NA}$ & \\
$\quad 61-80$ & 1.33 & $0.69-2.51$ & \\
$\quad 41-60$ & 1.47 & $0.67-3.23$ & \\
$\quad \leq 40$ & 2.84 & $1.09-7.38$ & \\
$\mathrm{FEV}_{1} / \mathrm{FVC}$ & & & .031 \\
$71+$ & 1.00 & $\mathrm{NA}$ & \\
$\quad 61-70$ & 0.88 & $0.42-1.82$ & \\
$51-60$ & 1.65 & $0.73-3.72$ & \\
$\quad \leq 50$ & 2.67 & $1.15-6.17$ & \\
& & & \\
* See Reference 28. & & & \\
NA = not applicable & & & \\
FVC $=$ forced vital capacity & & & \\
\end{tabular}

$1.02-1.62, P=.03)$, respectively. When analyzed as a categorical variable, more severe air flow obstruction was associated with greater likelihood of lung cancer (Table 6). There was no statistical association between percent volume of emphysema on chest CT scan and prevalent or incident lung cancer $(P>.05)$. Total lung volume measured on chest $\mathrm{CT}$ was significantly higher in patients with lung cancer than control subjects $(5,397 \mathrm{~mL}$ vs $5,042 \mathrm{~mL}$, $P=.01)$.

In summary, presence of air flow obstruction and its severity increase the likelihood of developing lung cancer, but the role of emphysema is not established. One possibility is that direct airway injury by smoking is the common risk factor for air flow obstruction and bronchogenic (ie, airway origin) lung cancer, while emphysema per se is less associated with bronchogenic lung cancer, as it is a non-airway injury of smoking.

\section{Are Genetic Studies Helpful in COPD Phenotype Definitions?}

Genetic studies are a promising area of investigation in obstructive lung disease, both in COPD and asthma. ${ }^{29}$ But as Weiss writes, quoting Winston Churchill, "It is not the beginning of the end, but it might be the end of the beginning." 29 Both from a mechanism and clinical standpoint, other than the long-established information we have about alpha- 1 antitrypsin deficiency (AATD) and emphysema, this rapidly growing area is still in its early stage.

The genetic disease AATD does cause emphysema that has a specific therapy depending on the patient's phenotype. As such, detection of this phenotype in patients with COPD is of potential therapeutic consequence. There is evidence that testing for and detection of AATD still re- mains low despite joint ATS-ERS guidelines on AATD recommending testing on patients with fixed air flow obstruction. ${ }^{30,31}$ Jain and colleagues at Cleveland Clinic examined using results of a physician requested PFT to trigger a message in the electronic medical record to consider testing for this condition. ${ }^{32}$ In patients with an $\mathrm{FEV}_{1} /$ FVC $<0.70$ and $\mathrm{FEV}_{1}<80 \%$ predicted, the physician received a clinical decision support message via the electronic health record suggesting that an AATD serum level or phenotype test be performed, unless a result was already available or specific alternative diagnoses were present. It also linked the provider to background information and guideline-based testing strategies. Although this resulted in significantly increased AATD tests performed after the alert $(15.1 \%$ vs $4.7 \%$ of eligible patients, $P<.001)$, the rate of detection of AATD decreased nonsignificantly (5.3\% vs $8.9 \%$ at baseline), and the diagnosis of the PiZZ phenotype was unchanged $(2.6 \%$ vs $3.2 \%$ baseline, $P=.88$ ). This suggests that using the results of PFTs resulted in increased AATD tests being performed, but did not result in increased case-finding of emphysema patients who might benefit from AATD replacement therapy.

\section{Summary}

Although we have long used subtype descriptors such as pink puffer and blue bloater in COPD, we are still at the early phase of finding phenotypes that are useful for guiding therapeutic decisions in this patient group. However, many phenotypic measurements of severity correlate with mortality in COPD: $\mathrm{FEV}_{1}$, IC/TLC, $\mathrm{D}_{\mathrm{LCO}}$, 6-min walk distance, and maximum $\mathrm{O}_{2}$ consumption or maximum watts on exercise testing. It appears that composite parameters, such as the BODE index, perform better, likely because they capture different aspects of severity that affect functional impairment and risk of death. In patients with air flow obstruction, the presence of bronchodilator responsiveness is just a relative feature that aids in the distinction of asthma from COPD, but is not diagnostic in this use. Although the finding of a normal $\mathrm{D}_{\mathrm{LCO}}$ helps to rule out exercise-induced $\mathrm{O}_{2}$ desaturation in COPD, those with a low $\mathrm{D}_{\mathrm{LCO}}$ need exercise measurements to confirm desaturation. At this time, PFT patterns alone do not define subsets that respond to particular therapies. Patients with COPD have a higher incidence of lung cancer. Both the presence of air flow obstruction and its severity increase the risk of lung cancer in COPD patients. When trying to distinguish asthma from COPD, inflammatory biomarkers (exhaled nitric oxide, sputum and bronchoalveolar lavage eosinophilia) are helpful. Genetics is a promising area to elucidate pathophysiology and treatment for asthma and COPD, but currently AATD is the only genetically determined phenotype that has relevance for COPD management. Our current concepts of asthma, COPD, and subtypes of these 


\section{Which Pulmonary Function Tests Best Differentiate Between COPD Phenotypes?}

obstructive lung diseases do not always help us with therapeutic decision-making. The best promise for the future seems to be in composite phenotypes or scores, both for distinguishing asthma from COPD, and for guiding therapeutic options. A new approach to diagnostic classification may be more helpful. If instead we start from outcomes of interest, perhaps we can work back to predictors of these outcomes, and organize new diagnostic entities that have predictive relevance for treatment choices, functional outcomes, and mortality.

\section{REFERENCES}

1. Mason RJ, Broaddus VC, Martin T, King T Jr, Schraufnagel D, Murray JF, Nadel JA. Murray and Nadel's textbook of respiratory medicine, 5th edition. Philadelphia: Saunders/Elsevier; 2010.

2. Han M, Agusti A, Calverley PM, Celli BR, Criner G, Curtis JL, et al. Chronic obstructive pulmonary disease phenotypes: the future of COPD (clinical commentary). Am J Respir Crit Care Med 2010; 182(5):598-604

3. National Emphysema Treatment Trial Research Group. A randomized trial comparing lung-volume-reduction surgery with medical therapy for severe emphysema. N Engl J Med 2003;348(21): 2059-2073.

4. Pelligrino R, Viegi G, Brusasco V, Crapo RO, Burgos F, Casaburi R, et al. Interpretative strategies for lung function tests. Eur Respir J 2005;26(5):948-968.

5. Rabe KF, Hurd S, Anzueto A, Barnes PJ, Buist SA, Calverley P, et al. Global strategy for the diagnosis, management, and prevention of chronic obstructive pulmonary disease: GOLD executive summary. Am J Respir Crit Care Med 2007;176(6):532-555.

6. Celli BR, Cote CG, Marin JM, Casanova C, Montes de Oca M, Mendez RA, et al. The body-mass index, airflow obstruction, dyspnea, and exercise capacity index in chronic obstructive pulmonary disease. N Engl J Med 2004;350(10):1005-1012.

7. Kesten S, Rebuck AS. Is the short-term response to inhaled Badrenergic agonist sensitive or specific for distinguishing between asthma and COPD? Chest 1994;105(4):1042-1045.

8. Tashkin DP, Celli B, Decramer M, Liu D, Burkhart D, Cassino C, Kesten S. Bronchodilator responsiveness in patients with COPD. Eur Respir J 2008;31(4):742-750.

9. Fabbri LM, Romagnoli M, Corbetta L, Casoni G, Busljetic K, Turato $\mathrm{G}$, et al. Differences in airway inflammation in patients with fixed airflow obstruction due to asthma or chronic obstructive pulmonary disease. Am J Respir Crit Care Med 2003;167(3):418-424.

10. Weatherall M, Travers J, Shirtcliffe PM, Marsh SE, Williams MV, Nowitz MR, et al. Distinct clinical phenotypes of airways disease defined by cluster analysis. Eur Respir J 2009;34(4):812-818.

11. Kuhn TS. The structure of scientific revolutions, 3rd edition. Chicago: University of Chicago; 1996.

12. Hankinson JL, Odencrantz JR, Fedan KB. Spirometric reference values from a sample of the general US population. Am J Respir Crit Care Med 1999;159(1):179-187.

13. Hansen EF, Phanareth K, Laursen LC, Kok-Jensen A, Dirksen A. Reversible and irreversible airflow obstruction as predictor of overall mortality in asthma and chronic obstructive pulmonary disease. Am J Respir Crit Care Med 1999;159(4 Pt 1):1267-1271

14. Hoogendoorn M, Feenstra TL, Hoogenveen RT, Al M, Rutten-van Mölken. Association between lung function and exacerbation frequency in patients with COPD. Int J Chron Obstruct Pulmon Dis 2010;5:435-444.
15. West WW, Nagai A, Hodgkin JE, Thurlbeck WM. The national institutes of health intermittent positive pressure breathing trial: pathology studies. III. The diagnosis of emphysema. Am Rev Respir Dis 1987;135(1):123-129.

16. Klein JS, Gamsu G, Webb WR, Golden JA, Müller NL. Highresolution CT diagnosis of emphysema in symptomatic patients with normal chest radiographs and isolated low diffusing capacity. Radiology 1992;182(3):817-821.

17. Lee SL, Ra SW, Chae EJ, Seo JB, Lim SY, Kim TH, et al. Validation of the lower limit of normal diffusing capacity for detecting emphysema. Respiration 2011;81(4):287-293.

18. MacIntyre N, Crapo RO, Viegi G, Johnson DC, van der Grinten CP, Brusasco V, et al. Standardisation of the single-breath determination of carbon monoxide uptake in the lung. Eur Respir J 2005;26(4): 720-735.

19. Owens GR, Rogers RM, Pennock BE, Levin D. The diffusing capacity as a predictor of arterial oxygen desaturation during exercise in patients with chronic obstructive disease. N Engl J Med 1984; 310(19):1218-1221.

20. Ries AL, Farrow JT, Clausen JL. Pulmonary function tests cannot predict exercise-induced hypoxemia in chronic obstruction pulmonary disease. Chest 1988;93(3):454-459.

21. Hadeli KO, Siegel EM, Sherrill DL, Beck KC, Enright PL. predictors of oxygen desaturation during submaximal exercise in $8,000 \mathrm{pa}-$ tients. Chest 2001;120(1):88-92.

22. Miller A, Thornton JC, Warshaw R, Anderson H, Teirstein AS, Selikoff IJ. Single breath diffusing capacity in a representative sample of the population of Michigan, a large industrial state. Predicted values, lower limits of normal, and frequencies of abnormality by smoking history. Am Rev Respir Dis 1983;127(3):270-277.

23. American Thoracic Society. ATS statement: guidelines for the sixminute walk test. Am J Respir Crit Care Med 2002;166(1):111-117. http://thoracic.org/statements/resources/pfet/sixminute.pdf. Accessed October 31, 2011.

24. Salzman SH. The six-minute walk test: clinical and research role, technique, coding, and reimbursement. Chest 2009;135(5):1345-1352.

25. Pichurko B. Exercising your patient: which test(s) and when? Respir Care 2012;57(1):100-110; discussion 110-113.

26. Casanova C, Cote C, de Torres JP, Aguirre-Jaime A, Marin JM, Pinto-Plata V, Celli BR. Inspiratory-to-total lung capacity ratio predicts mortality in patients with chronic obstructive pulmonary disease. Am J Respir Crit Care Med 2005;171(6):591-597.

27. Martinez FJ, Foster G, Curtis JL, Criner G, Weinmann G, Fishman A, et al; NETT Research Group. Predictors of mortality in patients with emphysema and severe airflow obstruction. Am J Respir Crit Care Med 2006;173(12):1326-1334.

28. Maldonado F, Bartholmai BJ, Swensen SJ, Midthun DE, Decker PA, Jett JR. Are airflow obstruction and radiographic evidence of emphysema risk factors for lung cancer? A nested case-control study using quantitative emphysema analysis. Chest 2010;138(6):12951302.

29. Weiss ST. What genes tell us about the pathogenesis of asthma and chronic obstructive pulmonary disease. Am J Respir Crit Care Med 2010;181(11):1170-1173.

30. Stoller JK, Sandhaus RA, Turino G, Dickson R, Rodgers K, Strange C. Delay in diagnosis of alpha1-antitrypsin deficiency: a continuing problem. Chest 2005;128(4):1989-1994.

31. American Thoracic Society, European Respiratory Society. ATS/ ERS statement: Standards for the diagnosis and management of individuals with alpha-1 antitrypsin deficiency. Am J Respir Crit Care Med 2003;168(7):818-900.

32. Jain A, McCarthy, Xu M, Stoller JK. Impact of a clinical decision support system in an electronic health record to enhance detection of alpha-1-antitrypsin deficiency. Chest 2011;140(1):198-204. 


\section{Which Pulmonary Function Tests Best Differentiate Between COPD Phenotypes?}

\section{Discussion}

Kaminsky: I want to say, Steve, I totally agree with you on the concepts that you were talking about, and want to remind everyone that there is a revolution going on in science right now. Bill, you alluded to this, too, and that's systems biology. It's basically trying to approach all of our ideas about disease from a totally unbiased point of view in a statistical way that involves modeling and testing and predictions to try to re-understand, if you will, what's going on out there. It's being applied finally in medicine; it's been done for a long time in other scientific disciplines.

MacIntyre: So, Steve, you seem to imply that doing more AAT [alpha-1 antitrypsin] testing is a good thing. The outcomes from replacing AAT are a small slowing of $\mathrm{FEV}_{1}$ decline and biochemical AAT levels higher in bronchoalveolar lavage fluid. The obvious question is "so what?" Does that really translate into some kind of meaningful outcome? I'm always concerned when we jump on bandwagons that are based only on physiologic end points. We really haven't looked at what this all means downstream and does it really pay off? Or, conversely, does a lifetime of AAT replacement therapy have its own problems and its own risks? Any thoughts on that?

Salzman: We've had AAT replacement around for quite a while, and I have to agree with you when it first came out I thought, "Why aren't we doing a randomized controlled trial of this stuff?' It was approved on the basis of a physiologic end point of increasing the levels in the bronchoalveolar lavage fluid. So I share some of the skepticism. I don't have a lot of personal experience in that area, I don't practice specifically in that area. I've found extremely few of them when I've sent the tests, and I think when you look at the guidelines for choosing patients for replacements, they're so complicated that you know this is clearly a controversial area.

It's sort of similar to the ATS guidelines $^{1}$ that came out a number of year ago for diagnosis and treatment of patients with Mycobacterium avium complex pulmonary disease, the guidelines have so many subsets and major and minor criteria that clearly it's a very controversial area. I would agree, we don't really know if we're helping patients with this replacement.

1. Griffith DE, Aksamit T, Brown-Elliott BA, Catanzaro A, Daley C, Gordin F, et al; ATS Mycobacterial Diseases Subcommittee. An official ATS/IDSA statement: diagnosis, treatment, and prevention of nontuberculous mycobacterial diseases. Am J Respir Crit Care Med 2007;175(4):367-416. DOI: 10.1164/rccm.200604-571ST. Erratum in: Am J Respir Crit Care Med 2007;175(7): 744-745. Dosage error in article text. http:// www.thoracic.org/statements/resources/ mtpi/nontuberculous-mycobacterialdiseases.pdf. Accessed September 26, 2011.

Miller: I'm very disturbed by adding that addendum to PFT reports. So, you have a 74 year-old heavy smoker and he has an $\mathrm{FEV}_{1}$ ratio below 0.7 and an $\mathrm{FEV}_{1}$ below $80 \%$ predicted, findings that are normal. Do we really think he's going to benefit by being tested for AAT? Like all things that you add automatically, most of the time they don't apply, or are irrelevant, or even ridiculous. Even if you truly have emphysema in a 74 yearold heavy smoker, I don't think there's much point in testing for AAT.

Salzman: Right, I'm not a strong advocate for this. This gets into the issue of guidelines implementation, an issue with all published sub-specialty guidelines, but we have the ATS/ERS 2003 guidelines $^{1}$ on AAT, which say we should be doing more testing in this area in order to find the patients.

1. American Thoracic Society/European Respiratory Society statement: standards for the diagnosis and management of individuals with alpha-1 antitrypsin deficiency. Am J Respir Crit Care Med 2003;168(7): 818-900. DOI: $10.1164 / \mathrm{rccm} \cdot 168.7 .818$. http://www.thoracic.org/statements/ resources/respiratory-disease-adults/ alpha1.pdf. Accessed September 26, 2011.

\section{Miller: Appropriately!}

Salzman: And many of us are not implementing it, so this is one way of increasing implementation.

Rundell:" I'd be interested to hear your thoughts on the desaturation curve from the step test with the cutoff of a $4 \%$ decrease in $\mathrm{S}_{\mathrm{aO}_{2}}$. How much do you think that's dependent upon the starting point? So, if the person's saturation level is very low to begin with, versus someone who's a bit higher? In terms of that $4 \%$ drop, I think the starting point might have something to do with it.

Salzman: Right, and Paul [Enright] may have some comments because he was involved with those data. I think you make an important point that somebody who's starting at $98 \%$ and goes down to $94 \%$ is a much larger drop in $\mathrm{P}_{\mathrm{O}_{2}}$, absolutely, so it's a more important physiologic change. On the other hand, it's probably not clinically important, since they're still in the $>90 \%$ range that we find safe.

Personally, I'm a bit of a therapeutic nihilist about $\mathrm{O}_{2}$ desaturation during exercise. What we know from the old NOTT [nocturnal oxygen therapy trial] and the companion British Medical Research Council trial is that supplementation of $\mathrm{O}_{2}$ is very helpful for mortality benefit in patients with COPD with low $\mathrm{P}_{\mathrm{O}_{2}}$ at rest, but we don't know that is the case in patients with exercise-only $\mathrm{O}_{2}$ desaturation. I don't know what we're improving by having people lug around even relatively lightweight $\mathrm{O}_{2}$. Sometimes I'm a skeptic about that, and will require not only improved $\mathrm{O}_{2}$ saturation measurements when I get patients with in-

\footnotetext{
* Kenneth W Rundell PhD, Pharmaxis, Exton, Pennsylvania.
} 


\section{Which Pulmonary Function Tests Best Differentiate Between COPD Phenotypes?}

terstitial lung disease or COPD on supplemental $\mathrm{O}_{2}$, but that we actually demonstrate improved exercise capacity when they carry around their $\mathrm{O}_{2}$. Sometimes I've even advocated, though it's hard to implement, that you should do a randomized controlled trial of giving them $\mathrm{O}_{2}$ versus room air at the same flow rate, because, unless you improve their exercise tolerance, I'm not sure we're helping them clinically.

Rundell: That's been done in athletes. We've measured athletes where their saturations would go down to $85 \%$ or $86 \%$, and in that group, if they exercised with 24-26\% supplemental $\mathrm{O}_{2}$, their $\dot{\mathrm{V}}_{\mathrm{O}_{2 \max }}$ would improve dramatically, in the $10 \%$ range, whereas for those whose saturation did not decrease below $92 \%$, supplemental $\mathrm{O}_{2}$ had no effect on $\dot{\mathrm{V}}_{\mathrm{O}_{2 \max }}$ improvement.

Salzman: Sometimes we're talking about a 90-pound severely compromised COPD patient for whom even a lightweight system is a lot to carry around. Unless we are improving their functional capacity, ambulation, and other activities, we may not be helping them with supplemental $\mathrm{O}_{2}$ during exercise.

Rundell: My point is that, when you're that low, if you use supplemental $\mathrm{O}_{2}$ your exercise tolerance is going to increase.

McCormack: I think the long-term $\mathrm{O}_{2}$ treatment trial will help answer some of those questions.

Enright: I would be remiss if I didn't make a comment about GOLD Stage I. I worry then when you put a label of COPD even on a 70 year-old smoker with a lower ratio but a normal $\mathrm{FEV}_{1}$, that the differential diagnosis of their dyspnea stops. About one fourth of such patients have heart failure. If an echocardiogram is not done or brain natriuretic peptide measured, heart failure will be missed. Such patients are often prescribed a COPD inhaler, which might hurt them rather than help them. We have very effective drugs for heart failure in older people with dyspnea. Too many smokers with a chronic cough are given the diagnosis of COPD when their chronic cough is actually due to gastroesophageal reflux disease, post-nasal drainage, or a side effect of their anti-hypertensive pill they're taking. So I really worry that pulmonologists will not look outside their own area of lung disease expertise to try and explain these symptoms.

McCormack: Just a comment about the phenotypes with asthma and COPD. This is coming from a perspective of studying responses to environmental triggers, especially pollution, in both COPD and asthma. In considering phenotypes, there are a couple that are maybe overlooked, such as non-atopic asthma and atopic COPD patients. Atopy changes over time and might be important in triggering exacerbations or modifying disease course in COPD, among the atopic subset. Non-atopic asthma is an understudied subset of asthma, and this subset might be at increased risk for later developing obstructive lung disease with overlapping features of COPD.

Rundell: Can I add one more question on that? In terms of distinguishing asthma and COPD, do you think the indirect challenge test has a role?

Salzman: You have the same problems with bronchial hyper-responsiveness as you do with the other tests, which is that there's a fair number of what we call COPD patients who have positive challenge tests: it is not specific for asthma. To go back to Paul's [Enright] earlier comments, I think it's an important issue you made about diagnostic narrowing. You see a lot of times with trainees when they present a patient to me and I say, "Well, how do you know the patient has COPD?"
"Well, he smoked and he has respiratory symptoms." And I remind them of the fairly small percentage of smokers who ever develop COPD, so we certainly haven't ruled in COPD by those 2 facts.

Your point about medications is important because, unlike $\mathrm{O}_{2}$ therapy for hypoxemic COPD, which we know improves survival, our medications are really not about improving survival. In heart failure those medications are about improving survival, and we have questions as to whether inhaled medications not only don't improve survival but may actually shorten survival when it comes to cardiovascular morbidity. I acknowledge that's an important issue.

Busse: Let me follow up with airway hyper-responsiveness in COPD. We haven't gotten to systems biology and need to look at responsiveness to therapy. I thought the part of the paper $^{1}$ from Woodruff at the University of California San Francisco that was very interesting was to look at a geneproduct pattern and then associate it with a response to treatment. Again, the limitations that exist now with COPD are basically the same treatments with asthma.

I think it would be helpful to look at some of these phenotypic situations with other various markers and then look at the response to therapy, either as a response to reduction of symptoms or future risks for exacerbations, which may be very different. I think if we could get more information and look at the response to treatment, we'd be far more sophisticated when we meet with patients and say, "We're making these recommendations based on these data, these characteristics, and these expectations."

Many times we start people on something and we never take them off. We really need to start to look at responsiveness along with everything else, as well as looking at end points and levels of control so we have some demarcation. The question that comes 


\section{Which Pulmonary Function Tests Best Differentiate Between COPD Phenotypes?}

up is, do we provide benefit? I don't think we know yet, but I think it's a reasonable way to start to look at it.

1. Woodruff PG, Modrek B, Choy DF, Jia G, Abbas AR, Ellwanger A, et al. T-helper type 2-driven inflammation defines major subphenotypes of asthma. Am J Respir Crit Care Med 2009;180(5):388-395.

Pichurko: I would echo the comments about the overall value of therapy and the discipline required of the doctor in initiating therapy. Not only moderately obstructive, but a good fraction of mildly obstructive individuals are often automatically treated, forgetting the fact that this is principally palliative treatment without prolongation of life benefits. Commonly, patients in the range of moderate obstruction will function well, particularly if they're otherwise fit and healthy. In such cases, to incur $\$ 250$ to $\$ 500$ monthly expenses for a lifetime may not be justified in the absence of demonstrable improvement. Clearly, efforts to achieve tobacco cessation, and to support hypoxia deserve uniform treatment, due to their demonstrable importance and benefit. In remaining areas, where subjective complaints of limitation and dyspnea are marginal, a limited trial of one to two months of therapy may be of value to demonstrate benefit to both patient and physician, prior to long-term commitments.

Salzman: I would agree that we need to operationalize this in our individual care of patients. What I find myself doing is, I will take a patient who is in that GOLD I or sometimes even GOLD 0, who may be saying, "I don't have much in the way of symptoms," but sometimes I'll start a therapeutic challenge trial and say, "Why don't you try these medications? We'll have you come back and repeat spirometry, take another history, and see how you're doing."

I certainly think there are many people who get into a cycle of inactivity who don't realize that they have exercise and activity limitation. I wouldn't want to under-treat patients, but I agree that we have to be cautious about over-treating, because there is that tendency to start them and not stop them. With individual patients, the message we should be sending out is reevaluate whether this medication is having enough benefit to continue.

Busse: To expand on what was said, I think we tend to look at concrete measurements like changes in pulmonary function, but that may not be the end result we need to look at. Again, when parents are asked about their children with asthma as to how far the child walks, parents thought their kids performed normally. With pedometers, kids with asthma walked $3 \mathrm{~km}$ versus the normal 6. It's sort of a downregulation of what their expectations are. I think patients tend to minimize things in attempts to be normal. When we do probing, we find out there are limitations to their activity and these are end points we also have to look at.
Salzman: I would agree with that. This is a PFT conference, but healthrelated quality of life outcome measures-which are used mostly in clinical trials, and we use them in very informal ways when we take histories in following individual patients-but I think it would be a challenge to incorporate those tools into individual practice, since we're instrumentfocused people. There are activitymeasuring devices that are being increasingly used in clinical trials that are getting to be cheap enough and good enough that maybe we'll be able to start using them in actual practice settings to really measure people's activity levels. It may be a more important outcome for COPD and asthma, as well as a lot of our other patients.

Coates: I'd like to echo that, because some of my general pediatric colleagues feel that you can make a diagnosis of exercise limitation purely by history alone. We get these children with asthma who are substantially obstructed, and we have the history of "I don't like doing sports, I really prefer to watch TV or play computer games." Once we start treating them and they feel better, it's a totally different child. The patients do downregulate what their expectations of physical activities are. I think we are easily misled by histories that suggest no limitations, when they actually do have them, and if we treat their airway disease, their exercise limitation improves.

This article is approved for Continuing Respiratory Care Education credit. For information and to obtain your CRCE

(free to AARC members) visit www.RCJournal.com 